\title{
Effects of proportional assist ventilation on exercise tolerance in COPD patients with chronic hypercapnia
}

\author{
L. Bianchi*, K. Foglio*, M. Pagani*, M. Vitacca*, A. Rossi**, N. Ambrosino*
}

Effects of proportional assist ventilation on exercise tolerance in COPD patients with chronic hypercapnia. L. Bianchi, K. Foglio, M. Pagani, M. Vitacca, A. Rossi, N. Ambrosino. CERS Journals Ltd 1998.

ABSTRACT: This study investigates the impact of proportional assist ventilation (PAV), a new mode of partial ventilatory support, on exercise tolerance and breathlessness in severe hypercapnic chronic obstructive pulmonary disease (COPD) patients. We also examined the effects of continuous positive airway pressure (CPAP) and pressure support ventilation (PSV). On two consecutive days, 15 stable hypercapnic COPD patients underwent four endurance tests on a cycle ergometer at $80 \%$ of their maximal workrate, receiving, via a nasal mask in random order, either: 1) sham ventilation (CPAP: 1 cmH 20$)$; 2) CPAP $\left(6 \mathrm{cmH}_{2} \mathrm{O}\right)$; 3) PSV (inspiratory pressure support: 12-16 $\mathrm{cmH}_{2} \mathrm{O}$; expiratory positive airway pressure (EPAP): $1 \mathrm{cmH}_{2} \mathrm{O}$ ); or 4) PAV $\left(8.6 \pm 3.6 \mathrm{cmH}_{2} \mathrm{O} \cdot \mathrm{L}^{-1}\right.$ and $3 \pm 1.3 \mathrm{cmH}_{2} \mathrm{O} \cdot \mathrm{L}^{-1} \cdot \mathrm{S}^{-1}$ of volume and flow assistance, respectively plus EPAP: $1 \mathrm{cmH}_{2} \mathrm{O}$ ). Oxygen supply was standardized to maintain an arterial oxygen saturation $\left(\mathrm{Sa}_{\mathrm{a}} \mathrm{O}_{2}\right)$ of $92-93 \%$. Breathing pattern and minute ventilation (by respiratory inductive plethysmography), pulse oximetry, end tidal partial pressure of $\mathrm{CO}_{2}$, cardiac frequency and sensations of dyspnoea and leg discomfort (by Borg scale) were monitored.

In comparison to sham ventilation, PAV, PSV and CPAP were able to increase the endurance time (from 7.2 \pm 4.4 to $12 \pm 5.6,10 \pm 5.2$ and $9.6 \pm 4.6 \mathrm{~min}$, respectively) and to reduce dyspnoea and oxygen flow to the nasal mask. However, the greatest improvement was observed with PAV.

We conclude that PAV delivered by nasal mask can im-prove exercise tolerance and dyspnoea in stable hypercapnic COPD patients and hence this mode of ventilatory support may be useful in respiratory rehabilitation programmes. Eur Respir J 1998; 11: 422-427.

Breathlessness is the most common symptom that limits exercise in patients with chronic obstructive pulmonary disease (COPD) and the major reason for referral to respiratory rehabilitation programmes. These usually include endurance exercise training at different levels of intensity, which may influence the physiological benefit of the programme $[1,2]$. Different reports have shown that breathing oxygen-enriched air, administration of continuous positive airway pressure (CPAP) or pressure support ventilation (PSV) can all improve exercise tolerance and breathlessness in stable COPD patients [3-8]. Recently, it has been indicated that a new mode of partial ventilatory assistance, proportional assist ventilation (PAV), can also improve exercise tolerance in COPD patients [9].

In the PAV mode, the ventilator is designed to generate flow and volume in proportion to the patient's inspiratory instantaneous effort [10-12], synchronizing the end of the ventilatory inspiratory cycle with the end of the patient's inspiratory effort. Furthermore, the level of pressure delivered to the patient increases and decreases according to the patient's ventilatory demand. PAV has been used to unload the inspiratory muscles for the treatment of patients with acute respiratory failure [11, 13-16], as well as in a noninvasive manner [17].
*Fondazione Salvatore Maugeri IRCCS Servizio di Fisiopatologia Respiratoria, Centro Medico di Gussago (BS, Italy). **Divisione di Pneumologia, Azienda Ospedaliera di Verona, Ospedale Maggiore di Borgo Trento, Verona, Italy.

Correspondence: L. Bianchi Fondazione S, Maugeri IRCCS

Fisiopatologia e Fisioterapia Respiratoria Day Hospital Pneumologico

Centro Medico

Via Pinidolo 23

25064 Gussago (BS)

Italy

Fax: 39302521718

Keywords: Continuous positive airway pressure

mechanical ventilation noninvasive ventilation pressure support ventilation pulmonary rehabilitation respiratory insufficiency

Received: March 211997

Accepted after revision November 71997
As a consequence of the proportionality and adaptability of the ventilatory support to the intensity and timing of spontaneous ventilatory patterns, PAV should be of particular value to support exercise training. In a small group of severe, stable COPD patients, Dolmage and GoLDSTEIN [9] found that PAV increased exercise tolerance. We wondered whether that approach could be extended to more severe COPD patients, namely those with chronic respiratory failure and carbon dioxide retention. In fact, the recent development of new therapeutic approaches, such as lung transplantation and lung volume reduction surgery, mean that severe COPD patients, even those with chronic respiratory failure, are candidates for rehabilitation programmes.

Therefore, this study was undertaken to investigate the impact of PAV on exercise tolerance and breathlessness in severe hypercapnic COPD patients. We also examined the effects of more conventional modes of partial ventilatory support such as CPAP and PSV.

\section{Methods}

Patients gave their informed consent to participate into the study which was approved by the Ethics committee of S. Maugeri Foundation and was conducted according to the declaration of Helsinki. 
Table 1. - Demographic, anthropometric and functional characteristics of the patients in the study

\begin{tabular}{|c|c|}
\hline Characteristic & \\
\hline Age yrs & $64 \pm 8$ \\
\hline Sex M/F & $14 / 1$ \\
\hline Weight $\mathrm{kg}$ & $77 \pm 15$ \\
\hline Height $\mathrm{cm}$ & $165 \pm 4$ \\
\hline $\mathrm{BSA} \mathrm{m} \mathrm{m}^{2}$ & $1.84 \pm 0.16$ \\
\hline IBW \% & $119 \pm 21$ \\
\hline FEV $1 \%$ pred & $32 \pm 10$ \\
\hline FVC $\%$ pred & $50 \pm 16$ \\
\hline $\mathrm{FEV} 1 / \mathrm{FVC} \%$ & $51 \pm 12$ \\
\hline FRC $\%$ pred & $156 \pm 41$ \\
\hline MIP \% pred & $50 \pm 21$ \\
\hline MEP $\%$ pred & $75 \pm 23$ \\
\hline$P_{a}, \mathrm{O}_{2} \mathrm{kPa}$ & $6.9 \pm 0.5$ \\
\hline $\mathrm{Pa}_{\mathrm{a}} \mathrm{CO}, \mathrm{kPa}$ & $6.9 \pm 0.9$ \\
\hline $\mathrm{pH}$ & $7.38 \pm 0.03$ \\
\hline Max load W & $67 \pm 25$ \\
\hline
\end{tabular}

Values are presented as mean \pm SD, with the exception of sex, which is given as absolute number. M: male; F: female; BSA: body surface area; IBW: ideal body weight; FEV1: forced expiratory volume in one second; $\%$ pred: $\%$ predicted; FVC: forced vital capacity; FRC: functional residual capacity; MIP: maximal inspiratory pressure; MEP: maximal expiratory pressure; $P \mathrm{a}, \mathrm{O}_{2}$ : arterial oxygen tension at rest; $P_{\mathrm{a}, \mathrm{CO}_{2}}$ : arterial carbon dioxide tension at rest, breathing $21 \% \mathrm{O}_{2}$.

\section{Patients}

Fifteen stable COPD patients with chronic hypercapnia entered the study. COPD was defined according to American Thoracic Society (ATS) criteria [18]. One patient had been submitted to pneumonectomy 8 yrs previously. Patients with overt cardiovascular or musculoskeletal disease, other organ failure, cancer and inability to co-operate were excluded from the study. Demographic, anthropometric and functional characteristics of patients are shown in table 1 . At the time of the study, the patients had been free from exacerbations for at least 1 month. All of the patients were on long-term oxygen therapy, whereas no patient was on long-term home mechanical ventilation (MV), although five patients had experienced noninvasive PSV at least 3 months before the study. All patients were receiving inhaled bronchodilators as regular treatment. No changes in medication or oxygen therapy were made during the week preceding the study.

\section{Measurements}

Pulmonary function tests. Lung volumes and forced vital spirometry (forced vital capacity (FVC)) were measured with a constant volume body plethysmograph (Medical Graphic Corp, St. Paul, MN, USA). The predicted values of QuANJER et al. [19] were used.

Respiratory muscle function. The respiratory muscle strength was assessed by measuring maximal inspiratory and expiratory pressures (MIP and MEP, respectively) at the level of functional residual capacity (FRC) and total lung capacity (TLC) respectively, according to the method of BLACK and HyatT [20] using a respiratory module system (Medical Graphic Corp, St. Paul, MN, USA). The predicted values of Bruschl et al. [21] were used.

Arterial blood gases. Arterial blood was sampled at the radial artery while the patients were in the sitting position and breathing room air for at least $1 \mathrm{hr}$. Arterial oxygen tension $\left(\mathrm{Pa}, \mathrm{O}_{2}\right)$, arterial carbon dioxide tension $\left(\mathrm{Pa}_{\mathrm{a}} \mathrm{CO}_{2}\right)$ and $\mathrm{pH}$ were measured by means of an automated analyser (ABL 300; Radiometer, Copenhagen, Denmark).

Exercise test. Symptom limited incremental exercise tests were performed on an electrically braked cycloergometer (Ergometris 800S; Sensormedics, Milwaukee, USA) using a standard $1 \mathrm{~min}$ incremental cycle exercise protocol. After stabilization and a 2 min period of unloaded pedalling at 60 cycles. $\mathrm{min}^{-1}$, the load was increased by $10 \mathrm{~W}$ each minute. The patients were strongly encouraged to cycle to the point of intolerable breathlessness, discomfort or exhaustion, until the maximal cardiac frequency $(f C)$ was achieved or an abnormal electrocardiogram (ECG) was noted (symptom-limited exercise test).

Monitoring. Arterial oxygen saturation $\left(\mathrm{Sa}_{\mathrm{a}} \mathrm{O}_{2}\right)$ was continuously monitored by pulse oximetry (Oxicap Monitor; Ohmeda, Louisville, CO, USA). End-tidal carbon dioxide tension $\left(P\right.$ et, $\left.\mathrm{CO}_{2}\right)$ was monitored continuously at the mask by means of a capnograph (Oxicap Monitor) and recorded each minute and at the end of exercise.

Breathing pattern. Time course of respiratory frequency $(f \mathrm{R})$, tidal volume $(V \mathrm{~T})$, minute ventilation $\left(V^{\prime} \mathrm{E}\right)$, respiratory timing (inspiratory time $(t \mathrm{I})$, expiratory time $(t \mathrm{E})$ and duty cycle $(t \mathrm{I} /$ tot $))$ and mean inspiratory flow $(V \mathrm{~T} / t \mathrm{I})$ were assessed, evaluating thoracic and abdominal movements by means of respiratory inductance plethysmography (RIP) (Respitrace plus; Ambulatory Monitoring, Ardsley, NY, USA). Quantitative diagnostic calibration [22] was performed calibrating the sum of rib cage and abdominal signals against the signal of $V \mathrm{~T}$ by the spirometer with the patients at rest in the sitting position on the cycloergometer. All these parameters were stored in a memory and analysed using dedicated computer software (Respitrends; Ambulatory Monitoring, Ardsley, NY, USA). Ten consecutive breaths were analysed at baseline, after each minute of endurance test and at the end of exercise and mean values were used for the subsequent analysis. Reliability of RIP during exercise and during positive pressure ventilation has been reported previously [5, 23, 24].

Subjective sensations. Subjective rating of dyspnoea and sensation of leg discomfort was performed by means of a modified Borg scale [25].

\section{Ventilatory settings}

PAV was delivered by means of a prototype portable ventilator (Respironics, Murrysville, PA, USA) able to compensate for leaks, through a nasal mask (Respironics, Murrysville, PA, USA) with adequate size for each patient nose. The device was equipped with the Sanders NRV-2 valve (Respironics) to prevent carbon dioxide rebreathing [26]. A complete description of PAV can be found elsewhere [25]. Briefly, adjustment of PAV entails levels for volume-related assist (VA) and flow-related assist (FA) according to the equation of motion [27]:

$$
P \text { appl }=P 0+V \times E+V^{\prime} \times R
$$

where $P$ appl is the pressure applied to inflate the respiratory system, either by the patient's contracting inspiratory 
muscles or by the ventilator or by the combination of both, $P 0$ is the elastic recoil pressure at the end of the expiration which is zero if the lung inflation starts from the elastic equilibrium volume of the respiratory system; $V$ and $V^{\prime}$ are the inspired volume and flow respectively, $E$ is the total respiratory system elastance and $R$ is total flow resistance. Therefore, $E$ and R should ideally be known to set PAV appropriately. Since measurements of $E$ and $R$ are not routinely performed in patients, they had to be done at the time of the study. We used the "run-away" method as described by Younes and co-workers [10-12]. Since a display of the ventilator prototype provided continuous recording of flow, volume and airway pressure $(P a w)$, through which occurrence of air leaks was eventually recorded, the "run-away" phenomenon was observed on that display. To measure $E$, FA was set at $1 \mathrm{cmH}_{2} \mathrm{O} \cdot \mathrm{L}^{-1} \cdot \mathrm{s}^{-1}$ whereas VA was set at $2 \mathrm{cmH}_{2} \mathrm{O} \cdot \mathrm{L}^{-1}$, then VA was raised in steps of $2 \mathrm{cmH}_{2} \mathrm{O} \cdot \mathrm{L}^{-1}$ until the "run-away" phenomenon occurred. The patients' $E$ was assumed to be the "runaway" value minus $2 \mathrm{cmH}_{2} \mathrm{O} \cdot \mathrm{L}^{-1}$. Likewise, $R$ was measured by setting VA and FA at $2 \mathrm{cmH}_{2} \mathrm{O} \cdot \mathrm{L}^{-1}$ and $1 \mathrm{cmH}_{2} \mathrm{O}$. $\mathrm{L}^{-1} \cdot \mathrm{s}^{-1}$ respectively, then $\mathrm{FA}$ was raised in steps of 1 $\mathrm{cmH}_{2} \mathrm{O} \cdot \mathrm{L}^{-1} \cdot \mathrm{s}^{-1}$ until the "run-away" phenomenon occurred. The values of the FA at the "run-away" minus $1 \mathrm{cmH}_{2} \mathrm{O} \cdot \mathrm{L}$ ${ }^{1} \cdot \mathrm{s}^{-1}$ were assumed to reflect patients' flow resistances. Therefore, individual values of $E$ and $R$ were obtained for each patient before setting PAV.

$E$ and $R$ obtained with the "run-away" method were $10.5 \pm$ $4.6 \mathrm{cmH}_{2} \mathrm{O} \cdot \mathrm{L}^{-1}$ and $3.8 \pm 1.7 \mathrm{cmH}_{2} \mathrm{O} \cdot \mathrm{L}^{-1}$, respectively. PAV was set at a level corresponding to VA and FA at $80 \%$ of the individual values of $E$ and $R$. Therefore, the average PAV was $8.6 \pm 3.6 \mathrm{cmH}_{2} \mathrm{O} \cdot \mathrm{L}^{-1}$ and $3 \pm 1.3 \mathrm{cmH}_{2} \mathrm{O} \cdot \mathrm{L}^{-1} \cdot \mathrm{s}^{-1}$ of VA and FA, respectively. An end-expiratory positive airway pressure (EPAP) amounting to $1 \mathrm{cmH}_{2} \mathrm{O}$ was added to PAV. If necessary, because of either patients' discomfort or frequent display of "run-away" events, the settings of PAV could be changed during the exercise.

CPAP, PSV and sham ventilation were delivered by means of the same portable ventilator, nasal mask and circuits (Respironics) used for PAV. As suggested by KeLty et al. [6], PSV was applied at an inspiratory pressure level set for patient comfort (range 12-16 $\mathrm{cmH}_{2} \mathrm{O}$ ) and an EPAP of $1 \mathrm{cmH}_{2} \mathrm{O}$. CPAP was applied at $6 \mathrm{cmH}_{2} \mathrm{O}$ according to O'Donnell et al. [3, 4]. The sham ventilation was performed applying a CPAP of $1 \mathrm{cmH}_{2} \mathrm{O}$.

\section{Study protocol}

Before the study, all patients underwent a period of at least 1 week during which it was ensured that they were thoroughly acquainted with cycling, the breathing equipment, the nasal masks, the ventilator and the Borg scale. During that week, after performance of a symptom limited exercise test, all patients underwent two daily sessions of $10-20 \mathrm{~min}$ on the cycloergometer at $20-40 \%$ of their maximal load without breathing equipment [28].

In the following week, the patients performed four endurance tests (i.e. during PAV, CPAP, PSV, and sham ventilation) at $80 \%$ of maximal rate (table 1), in two consecutive days, at 08:00 $\mathrm{h}$ and 12:00 $\mathrm{h}$ according to a random order. The average workrate amounted to $53 \pm 22 \mathrm{~W}$. On the third day, an additional endurance test (control), was performed at the same workrate level, with the nose mask on but without any other breathing equipment. In this control condition we measured only the endurance time (ET), the dyspnoea score, pulse oximetry and $P$ et, $\mathrm{CO}_{2}$. As shown in table 1 , the patients recruited for this study had mild hypoxaemia during room air tidal breathing at rest. To prevent oxygen desaturation as well as worsening of hypoxaemia during exercise, a flow of oxygen-enriched air was continuously delivered via the mask to maintain $\mathrm{Sa}, \mathrm{O}_{2}$ at level of $92-93 \%$ in all the five trials [29]. The rate of oxygen supply (in L.min ${ }^{-1}$ ) was recorded each minute and at the end of the exercise.

The patients were given standard oral encouragement at each minute. At rest ( $5 \mathrm{~min}$ after adaptation to the nasal mask) and during unsupported and supported exercise at 1 min intervals, patients were asked their perceived breathlessness and sensation of leg discomfort by pointing to a number or phrase on a 10-point Borg scale set in large type on a sheet in front of them. Endurance test was stopped according to the same criteria as the incremental test. $f \mathrm{C}$ and cardiac rhythm were monitored with a three-lead ECG and blood pressure was measured with the cuff technique throughout each test.

\section{Data analysis}

Differences between and within treatment were evaluated by analysis of variance (ANOVA) for repeated measures. Student's paired t-test was used for comparison of control and sham endurance tests. A p-value of less than 0.05 was considered significant.

\section{Results}

PAV and the other modes of ventilatory support were well tolerated by all patients. Air leaks, monitored by means of the display of the ventilator, did not occur. All the pat-ients were instructed to breathe through the nose in the mask and to keep the mouth closed throughout the exercise test to prevent leaks. Neither discomfort nor adverse effects were observed throughout the study. In two pati-ents, two episodes of "run-away", probably due to chang-es in their respiratory mechanics, occurred during the trials with PAV and were corrected by slightly reducing the level of assistance.

Table 2. - Effects of different modes of mechanical ventilation on exercise tolerance, dyspnoea, leg discomfort and need of oxygen supply

\begin{tabular}{|c|c|c|c|c|c|}
\hline Parameter & Control & Sham & CPAP & PSV & PAV \\
\hline Endurance time min & $7.1 \pm 4.6$ & $7.2 \pm 4.4$ & $9.6 \pm 4.6^{*}$ & $10.5 \pm 2 *$ & $12.5 \pm 6 * \sharp \#$ \\
\hline Borg dyspnoea isotime & $6.3 \pm 1.4$ & $6.5 \pm 1.5$ & $5.3 \pm 1.9^{*}$ & $4.4 \pm 1.4 * \S$ & $4.2 \pm 1.9 * 8$ \\
\hline Borg leg discomfort isotime & $5.0 \pm 2.6$ & $5.4 \pm 1.9$ & $4.9 \pm 2.3$ & $4.1 \pm 2.2 *$ & $4.2 \pm 2.3^{*}$ \\
\hline $\mathrm{O}_{2}$ supply isotime $\mathrm{L} \cdot \mathrm{min}^{-1}$ & $3.8 \pm 1.8$ & $3.9 \pm 1.9$ & $3.7 \pm 2.0$ & $3.1 \pm 1.8 * \S$ & $3.4 \pm 1.9 *$ \\
\hline
\end{tabular}


The effects of PAV, PSV, CPAP, sham ventilation and control condition on the endurance time, the subjective sensations and the amount of oxygen supply, are shown in table 2. There was no difference between control condition and sham ventilation for any of the variables used to assess exercise tolerance. Henceforth, sham ventilation will be the reference to compare unsupported with supported exercise. With any ventilatory support the ET was longer. As illustrated in figure 1 PAV systematically improved individual values of ET compared to sham.

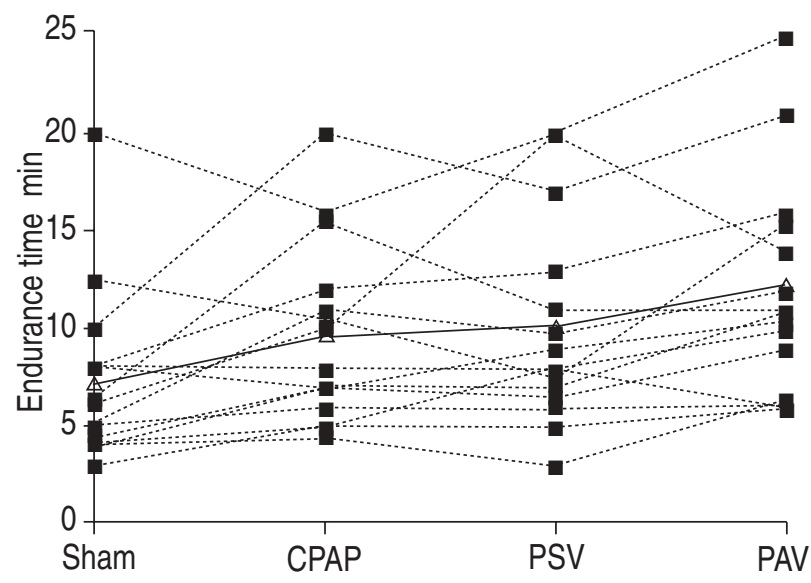

Fig. 1. - Individual (- - - - ) and mean (-ý-) values of endurance time in the different conditions. For significant differences and definitions see table 2 .

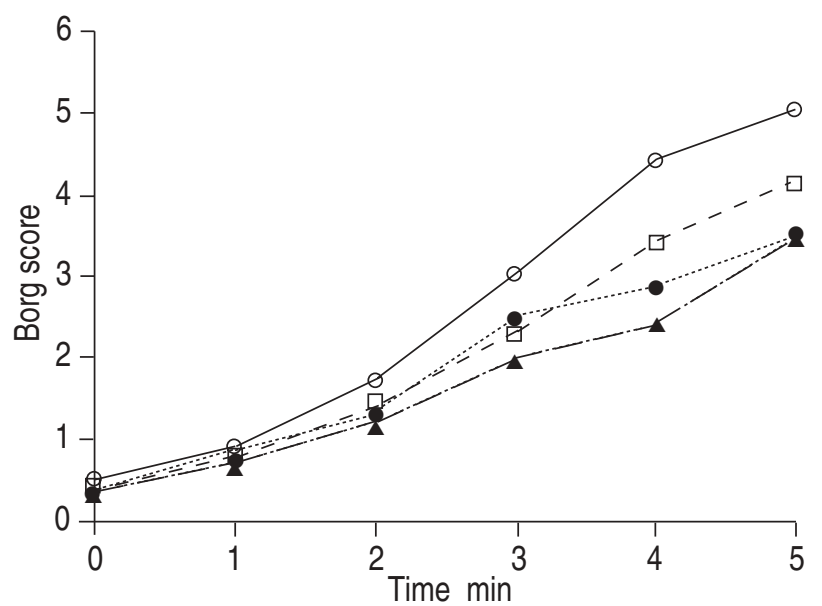

Fig. 2. - Mean values of breathlessness (Borg scale) at each minute of exercise until the fifth. - ○—: Sham; - - $\_-$: continuous positive airway pressure; - - - - : proportional assist ventilation; - - - - : pressure support ventilation.
Figure 2 shows relationships between breathlessness and duration of exercise. In comparison with sham, all modes of MV also resulted in reduction in dyspnoea at isotime. The improvement with PAV and PSV was greater than with CPAP (table 2). Similar results were obtained from the analysis of leg discomfort. The flow of oxygen needed to maintain $\mathrm{Sa}_{2} \mathrm{O}_{2}$ at the targeted level of 92-93\% was lower with PAV and PSV than with sham (table 2).

The effect of assisted ventilation on isotime breathing pattern is shown in table 3. At any step of exercise, isotime $V \mathrm{~T}$ and $V \mathrm{~T} / t \mathrm{I}$ were greater while $t \mathrm{I} / t$ tot was smaller with PAV and PSV compared to sham ventilation.

Exercise was associated with increase in isotime $f \mathrm{C}$ that was not different among conditions. In contrast the exercise associated increase in $P$ et, $\mathrm{CO}_{2}$ was smaller during supported than during sham ventilation exercise (table 3 ). It should be mentioned that $P$ et, $\mathrm{CO}_{2}$ was higher during sham than during control cycling $(9.3 \pm 1.4$ versus $8.1 \pm 1.7 \mathrm{kPa}$ at isotime, $\mathrm{p}<0.05$ )

\section{Discussion}

The results of this study show that PAV, delivered by nasal mask and for the settings examined in this protocol, improves exercise tolerance and breathlessness in severe hypercapnic COPD patients. We also found that PSV and, to a lesser extent CPAP, again for the settings examined in this study, can improve exercise tolerance in those patients. To our knowledge this is the first study to evaluate the effects of PAV delivered by nasal mask in severe stable COPD patients with chronic hypercapnia.

The present results extend the observation of DoLmage et al. [9] who found that PAV and CPAP provided ventilatory assistance during cycle exercise sufficient to increase ET in severe COPD patients, but without respiratory in-sufficiency. Furthermore, HeRnANDEZ et al. [30] showed that PAV was able to increase ET in severe normocapnic COPD patients, whereas Chrusch et al. [31] found that the addition of PAV to oxygen and CPAP improved neither ET nor dyspnoea in those patients. However, the level of PAV assistance in that study [31], titrated to patient comfort, was lower than in the present study and in the studies by Hernandez et al. [30] and by Dolmage et al. [9].

The augmented ventilatory demand determined by exercise increases the workload on the inspiratory muscles to a point that might initiate a fatiguing process [32, 33]. Therefore, by unloading the inspiratory muscles PAV may be useful to improve exercise tolerance in these patients. Younes et al. [11] showed that in normal subjects undergo-

Table 3. - Effects of different modes of mechanical ventilation on cardiac function, end-tidal carbon dioxide tension $\left(P_{\mathrm{et}}, \mathrm{CO}_{2}\right)$ and breathing pattern at isotime

\begin{tabular}{lcccc}
\hline & Sham & CPAP & PSV & PAV \\
\hline$f \mathrm{C}$ beats $\cdot \mathrm{min}^{-1}$ & $116 \pm 17$ & $111 \pm 15$ & $112 \pm 10$ & $112 \pm 15$ \\
$P$ et, $\mathrm{CO}_{2} \mathrm{kPa}$ & $9.3 \pm 1.4$ & $8.0 \pm 1.2$ & $7.5 \pm 1.2 *$ & $7.4 \pm 1.0 * \S$ \\
$f \mathrm{R} \mathrm{breaths} \cdot \mathrm{min}^{-1}$ & $34 \pm 8$ & $32 \pm 8$ & $31 \pm 7$ & $30 \pm 7$ \\
$t \mathrm{I} \mathrm{s}$ & $0.81 \pm 0.23$ & $0.84 \pm 0.29$ & $0.81 \pm 0.21$ & $0.83 \pm 0.21$ \\
$t \mathrm{I} / t \mathrm{tot}$ & $0.44 \pm 0.06$ & $0.45 \pm 0.09$ & $0.39 \pm 0.05 * \S$ & $0.39 \pm 0.07 * \S$ \\
$V \mathrm{~T} \mathrm{~L}$ & $1.00 \pm 0.39$ & $1.07 \pm 0.39$ & $1.15 \pm 0.43^{*}$ & $1.14 \pm 0.47 *$ \\
$V^{\prime} \mathrm{E} \mathrm{L} \cdot \mathrm{min}^{-1}$ & $32.3 \pm 10.2$ & $32.6 \pm 11.3$ & $34.4 \pm 13$ & $33.8 \pm 13.1$ \\
$V \mathrm{~T} / t \mathrm{I} \mathrm{L} \cdot \mathrm{s}^{-1}$ & $1.27 \pm 0.43$ & $1.31 \pm 0.56$ & $1.50 \pm 0.62 * \S$ & $1.42 \pm 0.50^{*}$ \\
\hline
\end{tabular}

*: $\mathrm{p}<0.05$ versus sham; $\$$ : $\mathrm{p}<0.05$ versus CPAP. $f \mathrm{C}$ : cardiac frequency; $f \mathrm{R}$ : respiratory frequency; $t$ I: inspiratory time; $t$ tot: total respiratory time; $V \mathrm{~T}$ : tidal volume; $V^{\prime} \mathrm{E}$ : minute ventilation. For further definition refer to table 2. 
ing heavy exercise, PAV reduced the oesophageal pressure $(P$ oes $)$ swings giving a sensation of easier breathing. Although experimental data are lacking, it seems reasonable to hypothesize a similar mechanism to explain the improvement in exercise tolerance in severe COPD.

In line with other studies on severe normocapnic COPD patients [3-8], we found that CPAP and PSV can also improve the exercise tolerance in hypercapnic COPD patients. It has been shown that PSV reduces the diaphragmatic pressure-time product $(P$ tp,di), dyspnoea [33, 34], and slows the maximum relaxation rate of inspiratory muscles, an early marker of the fatigue process [7]. It has also been suggested that these patients can prolong exercise induced lactataemia if assisted with PSV [35]. Application of CPAP unloads the inspiratory muscles during exercise [5] mainly because it counterbalances the intrinsic positive end-expiratory pressure (PEEPi). In the present study we did not measure PEEPi during exercise, and the level of CPAP was set according to the literature [3, 4]. This lack of tailoring could explain why CPAP was not as efficient as PSV and PAV in improving endurance time and dyspnoea. PSV was also set, in the present study, according to literature [6], although the level was not fixed, but was chosen according to the comfort of individual patients. In contrast, PAV was tailored to the respiratory mechanics of individual patients, although the "run-away" method to measure $E$ and $R$ requires further validation. Therefore, under these circumstances, the difference between PAV and PSV might well reflect differences in individual settings rather than differences between ventilatory modes. Hence the conclusion that PAV is superior to PSV or CPAP to improve exercise tolerance is not warranted on the basis of our data. However, our results show that PAV can be profitably and safely used in the rehabilitation setting to increase the intensity level of training in hypercapnic COPD patients, for example those awaiting lung transplantation.

It has been claimed that the major advantage of PAV compared to conventional modes of partial ventilatory support is represented by its capability to match spontaneous changes in patients' ventilatory demands and pattern [12]. This should be particularly attractive during exercise where the breathing pattern changes rapidly to meet the metabolic requirements. However, to our knowledge, there is no experimental data, at the present time, to support this hypothesis. This should be addressed in future research in which possible pitfalls of PAV should be considered. A potential complication of PAV is that its appropriate setting requires measurement of the patient's respiratory mechanics. As previously mentioned, the "run-away" technique [12], as well as other recently suggested methods [36], needs further validation to be used in the clinical settings. Furthermore, it should be considered that patients' respiratory mechanics can change during exercise, for example PEEPi increases [5], and this profoundly affects the effect of PAV. However, in the present study, only on two occasions was it necessary to reduce PAV slightly to avoid "run-away" and no mention of changes in the PAV settings is reported by Dolmage and GoLDSTEIN [9].

In the present study, a nose mask was used, whereas in other studies either a full face mask $[6,7,35]$ or a mouthpiece $[3-5,8,9,31,34]$ was the interface between the patient and ventilator. Whether the difference in the devi- ces could affect the results remains to be established. However, in the present study the device was the same in all conditions.

Oxygen desaturation during exercise is usually most marked in patients with severe COPD [37]. Arterial hypoxaemia may directly impair exercise performance by reducing oxygen delivery to working muscles, causing ventilatory limitation, and impairing cardiac function. Therefore for ethical reasons we preferred to perform the study on oxygen and to avoid confounding factors, oxygen therapy was standardized to achieve a given $\mathrm{Sa}_{\mathrm{a}} \mathrm{O}_{2}$. The flow of oxygen-enriched air to maintain the targeted $\mathrm{Sa}_{\mathrm{a}} \mathrm{O}_{2}$ was slightly lower with PSV and PAV.

To prevent an enhancement of the exercise-induced increase in $\mathrm{CO}_{2}$ retention due to the rebreathing effect of the circuit, the Sanders NRV-2 valve was used [26, 38]. Despite that device, cycling, during sham ventilation was associated with significantly greater $P$ et, $\mathrm{CO}_{2}$ than control cycling with only the nose mask on. This seems to indicate a rebreathing effect. It seems unlikely that the better exercise tolerance observed with PAV and PSV can be ascribed to the lower $P$ et, $\mathrm{CO}_{2}$. In fact, ET of control and sham cycling were the same despite different levels of $P$ et, $\mathrm{CO}_{2}$. The use of $P$ et, $\mathrm{CO}_{2}$ assessment may be criticized as it has been shown that with PSV it may underestimate the real value of $P \mathrm{a}_{1} \mathrm{CO}_{2}$ [39], nevertheless we used this parameter only for monitoring purposes.

\section{Clinical implications}

Our results indicating, an increase in high-intensity endurance time with PAV and the other modes of ventilatory assistance may be promising, as these modes might allow the training stimulus to be increased above that possible in the absence of mechanical support [9]. The usefulness of PAV delivered by portable ventilators during exercise in pulmonary rehabilitation programmes should be assessed in additional studies.

In conclusion proportional assist ventilation delivered by a nasal mask was able to improve exercise tolerance and reduce dyspnoea in severe stable hypercapnic chronic obstructive pulmonary disease patients. Potential advantages and disadvantages of proportional assist ventilation compared to other modes of partial ventilatory assistance, such as continuous positive airway pressure and pressure support ventilation need further physiological studies. Additional information is also needed to elucidate the appropriate application of proportional assist ventilation in respiratory rehabilitation programmes, such as use as a bridge to lung transplantation for patients on the waiting list.

\section{References}

1. Lacasse Y, Wong E, Guyatt GH, Cook DJ, Goldstein RS. Meta-analysis of respiratory rehabilitation in chronic obstructive pulmonary disease. Lancet 1996; 348: 11151119.

2. Casaburi R, Patessio A, Ioli F, et al. Reductions in exercise lactic acidosis and ventilation as a result of exercise training in patients with obstructive lung disease. Am Rev Respir Dis 1991; 143: 9-18.

3. O'Donnell DE, Sanij R. Younes M. Improvement in exer- 
cise endurance in patients with chronic airflow limitation using continuous positive airway pressure. Am Rev Respir Dis 1988; 138: 1510-1514.

4. O'Donnell DE, Sanij R, Giesbrecht G, Younes M. Effect of continuous positive airway pressure on respiratory sensation in patients with chronic obstructive pulmonary disease during submaximal exercise. Am Rev Respir Dis 1988; 138: $1185-1191$.

5. Petrov BJ, Calderini E, Gottfried SB. Effect of CPAP on respiratory effort and dyspnea during exercise in severe COPD. J Appl Physiol 1990; 69: 179-188.

6. Keilty SEJ, Ponte J, Fleming TA, Moxham J. Effect of inspiratory pressure support on exercise tolerance and breathlessness in patients with severe stable chronic obstructive pulmonary disease. Thorax 1994; 49: 990-994.

7. Polkey MI, Kyroussis D, Mills GH, et al. Inspiratory pressure support reduces slowing of inspiratory muscle relaxation rate during exhaustive treadmill walking in severe COPD. Am J Crit Care Med 1996; 154: 1146-1150.

8. Henke KG, Regnis JA, Bye PT. Benefits of continuous positive airway pressure during exercise in cystic fibrosis and relationship to disease severity. Am Rev Respir Dis 1993; 148: 1272-1276.

9. Dolmage TE, Goldstein RS. Proportional assist ventilation and exercise tolerance in subjects with COPD. Chest 1997; 111: 948-954.

10. Younes M. Proportional assist ventilation, a new approach to ventilatory support. Theory. Am Rev Respir Dis 1992; 145: 114-120.

11. Younes M, Puddy A, Roberts D, et al. Proportional assist ventilation. Results of a clinical trial. Am Rev Respir Dis 1992; 145: 121-125.

12. Younes M. Proportional assist ventilation. In: Tobin MJ, ed. Principles and Practice of Mechanical Ventilation. New York, McGraw-Hill inc. 1994; pp. 349-370.

13. Navalesi P, Hernandez P, Wongsa A, Laporta D, Goldberg $\mathrm{P}$, Gottfried SB. Proportional assist ventilation in acute respiratory failure: effects on breathing pattern and inspiratory effort. Am J Respir Crit Care Med 1996; 154: 1330-1338.

14. Ranieri MV, Ginliano R, Mascia L, et al. Patient-ventilator interaction during acute hypercapnia: pressure-support vs proportional-assist ventilation. J Appl Physiol 1996; 81: 426-436.

15. Marantz S, Patrick W, Webster K, Roberts D, Oppenheimer D, Younes M. Responses of ventilator dependent patients to different levels of proportional assist. J Appl Physiol 1996; 80: 397-403.

16. Ranieri MV, Grasso S, Mascia L, et al. Effects of proportional assist ventilation on inspiratory muscle effort in patients with chronic obstructive pulmonary disease and acute respiratory failure. Anesthesiology 1997; 86: 7991.

17. Patrick W, Webster K, Ludwig L, Roberts D, Wiebe P, Younes M. Noninvasive positive-pressure ventilation in acute respiratory distress without prior chronic respiratory failure. Am J Respir Crit Care Med 1996; 153: 10051011.

18. American Thoracic Society. Standards for the diagnosis and care of patients with chronic obstructive pulmonary disease and asthma. Am Rev Respir Dis 1987; 136: 225244.

19. Quanjer PH. Working Party on "Standardization of lung function test". Bull Eur Physiopathol Respir 1983; 19 (Suppl. 5): 7-10.

20. Black L, Hyatt R. Maximal airway pressures: normal values and relationship to age and sex. Am Rev Respir Dis 1969; 99: 696-702.

21. Bruschi C, Cerveri I, Zoia MC, et al. Reference values of maximal respiratory mouth pressures: A populationbased study. Am Rev Respir Dis 1992; 146: 790-793.

22. Sackner MA, Watson H, Belsito AS, et al. Calibration of respiratory inductive plethysmograph during natural breathing. J Appl Physiol 1989; 66: 410-420.

23. Ambrosino N, Nava S, Bertone P, Fracchia C, Rampulla C. Physiologic evaluation of pressure support ventilation by nasal mask in stable COPD patients. Chest 1992; 101: 385-391.

24. Nava S, Ambrosino N, Rubini F, et al. Effect of nasal pressure support ventilation and external PEEP on diaphragmatic activity in patients with severe stable COPD. Chest 1993; 103: 143-150.

25. Borg GAV. Psychophysical basis of perceived exertion. Med Sci Sports Exerc 1992; 14: 377-381.

26. Ferguson T Gilmartin M. $\mathrm{CO}_{2}$ rebreathing during BiPAP ventilatory assistance. Am J Respir Crit Care Med 1995; 151: 1126-1135.

27. Rodarte JR, Rehder K. Dynamics of respiration. In: Macklem PT, Mead J, eds. Handbook of Physiology. The Respiratory System. Bethesda, American Physiological Society, 1986; section 3, pp. 131-144.

28. Belman MJ, Brooks LR, Ross DJ, Moshenifar Z. Variability of breathlessness measurement in patients with chronic obstructive pulmonary disease. Chest 1991; 99: 566-571.

29. Siafakas NM, Vermeire P Pride NB, et al. ERS Consensus statement. Optimal assessment and management of chronic obstructive pulmonary disease (COPD). Eur Respir J 1995; 8: 1398-1420.

30. Hernandez P, Maltais F, Gursahaney A, LeBlanc P, Navalesi P, Gottfried SB. Proportional assist ventilation (PAV) improves exercise performance in severe COPD. Am J Respir Crit Care Med 1996; 154 (Suppl): A 172.

31. Chrusch C, Bauerie O, Younes M. The effect of proportional assist ventilation (PAV) on exercise endurance time in COPD. Am J Respir Crit Care Med 1996; 154 (Suppl): A171.

32. De Troyer A, Pride NB. The chest wall and respiratory muscles in chronic obstructive pulmonary disease. In: Roussos C, ed. The Thorax. New York, Marcel Dekker, 1995; pp. 1975-2006.

33. Kyroussis D, Polkey MI, Keilty SEJ, et al. Exhaustive exercise slows inspiratory muscle relaxation rate in chronic obstructive pulmonary disease. Am J Respir Crit Care Med 1996; 153: 787-793.

34. Maltais F Reissman H Gottfried SB. Pressure support reduces inspiratory effort and dyspnea during exercise in chronic airflow obstruction. Am J Respir Crit Care Med 1995; 151: 1027-1033.

35. Polkey MI, Kyroussis D, Fleming TA, Wood CN, Sherwood RA, Moxham J. Could inspiratory pressure support (IPS) be a useful adjunct in pulmonary rehabilitation? Thorax 1996; 51 (Suppl. 3): A26.

36. Younes M, Webster K, Kun J, Roberts D. A method for determining the pressure-flow $(\mathrm{P}-\mathrm{V})$ relation during proportional assist ventilation. Am J Respir Crit Care Med 1997; 155: A525.

37. Gallagher CG. Exercise limitation and clinical exercise testing in chronic obstructive pulmonary disease. Clin Chest Med 1994; 15: 305-326.

38. Lofaso F, Brochard L, Hang T, Lorino H, Harf A, Isabey D. Home versus intensive care pressure support devices. Experimental and clinical comparison. Am J Respir Crit Care Med 1996; 153: 1591-1599.

39. Sanders MH, Kern NB, Costantino JP, et al. Accuracy of end-tidal and transcutaneous $\mathrm{PCO}_{2}$ monitoring during sleep. Chest 1994; 106: 472-483. 